\title{
Hybrid-organic-inorganic anatase as a bifunctional catalyst for enhanced production of HMF from glucose in water
}

\author{
Carlos A. S. Lanziano ${ }^{[a, b]}$, Silvia F. Moya ${ }^{[a]}$, Dean. H. Barrett ${ }^{[a]}$, Erico Teixeira-Neto ${ }^{[c]}$, Reginaldo \\ Guirardello ${ }^{[b]}$, Felipe Souto da Silva, ${ }^{[e]}$ Roberto Rinaldi, ${ }^{[[]]}$Cristiane B. Rodella*[a]
}

\begin{abstract}
Herein, we report a synthetic route for the preparation of hybrid-organic-inorganic anatase (hybrid- $\mathrm{TiO}_{2}$ ) via a facile hydrothermal synthesis method employing citric acid. The synthetic approach results in a high surface area nanocrystalline anatase polymorph of $\mathrm{TiO}_{2}$. The uncalcined hybrid- $\mathrm{TiO}_{2}$ is directly studied here as the catalyst for the conversion of glucose into HMF. In the presence of the hybrid- $\mathrm{TiO}_{2}, \mathrm{HMF}$ yields up to $45 \%$ at glucose conversions up to $75 \%$ were achieved in water at $130^{\circ} \mathrm{C}$ in a monophasic batch reactor. As identified by Ti K-edge XANES, hybrid- $\mathrm{TiO}_{2}$ contains a large fraction of five-fold coordinatively unsaturated Ti(IV) sites, which act as the Lewis acid catalyst for the conversion of glucose into fructose. As citric acid is anchored in the structure of hybrid- $\mathrm{TiO}_{2}$, carboxylate groups seem to catalyse the sequential conversion of fructose into HMF. The fate of citric acid bounded to anatase and the Ti(IV) Lewis acid sites throughout recycling experiments is also investigated. In a broader context, the contribution outlines the importance of hydrothermal synthesis for the creation of waterresistant Lewis acid sites for the conversion of sugars. Most importantly, the utilisation of the hybrid- $\mathrm{TiO}_{2}$ with no calcination step contributes to dramatically decreasing the energy consumption in the catalyst preparation.
\end{abstract}

\section{Introduction}

5-Hydroxymethylfurfural (HMF) plays an important role in the development of the emerging bio-based economy. Owing to its structural features, HMF can be used as a platform chemical in the production of biofuels, pharmaceuticals and polymers. ${ }^{[1-4]}$ In aqueous media, HMF can be obtained from either fructose or glucose in the presence of heterogeneous catalysts. ${ }^{[1,4-9]}$ Nonetheless, HMF selectivity is low ( 12\%) due to the formation

[a] Mr. C. A. S. Lanziano, Dr. S. F. Moya, Dr. D. H. Barrett and Dr. C. B. Rodella*

Brazilian Synchrotron Light Laboratory (LNLS)

Brazilian Centre for Research in Energy and Materials (CNPEM)

CP 6192, CEP 13083-970, Campinas, SP, Brazil

Email: cristiane.rodella@Inls.br

[b] Mr. C. A. S. Lanziano, Dr. R. Guirardello

School of Chemical Engineering

University of Campinas

Av. Albert Einstein, 500, CEP 13083-852, Campinas, SP, Brazil

[c] Dr. E. T.-Neto

Brazilian Nanotechnology National Laboratory (LNNano)

Brazilian Centre for Research in Energy and Materials (CNPEM)

CP 6192, CEP 13083-970, Campinas, SP, Brazil

[d] F. de Souta da Silva, Dr. R. Rinaldi

Department of Chemical Engineering, Imperial College London

South Kensington Campus, SW7 2AZ, United Kingdom

Email: rrinaldi@ic.ac.uk

Supporting information available on www of levulinic acid, formic acid as well as humins..$^{[1,6,8]}$ Glucose is both widely available and cheaper than fructose. Thus, glucose is often the preferred starting material for the production of HMF. ${ }^{[3]}$ In this context, bifunctional catalysts capable of isomerising glucose into fructose and sequentially converting fructose into HMF are required ${ }^{[1,4,10-15]}$

To improve the conversion of glucose into HMF, several strategies-such as microwave-assisted heating, ${ }^{[7]}$ hot compressed water, ${ }^{\left[{ }^{[9]}\right.}$ biphasic reaction systems, ${ }^{[16,17]}$ and ionic liquids as the reaction media ${ }^{[18]}$ - have been investigated. Regarding the utilisation of multifunctional catalysts, ${ }^{[5,6,9,15,19-24]}$ anatase $\left(\mathrm{TiO}_{2}\right)$ holds promise as a catalyst for the high-yield production of HMF from glucose owing to several unique features. ${ }^{[5,7,8,23,25]}$ For instance, anatase shows a higher surface area, compared to the rutile and brookite polymorphs. Furthermore, the active sites required for the conversion of fructose into $\mathrm{HMF}$ are also present on $\mathrm{TiO}_{2}$ anatase phase. ${ }^{[5-}$ 7,15,23,25-27] In fact, Hara and co-workers showed that $\mathrm{TiO}_{2}$ contains water-tolerant Lewis acid sites, owing to the presence of coordinatively unsaturated $\mathrm{Ti}(\mathrm{IV})$ on the oxide surface. ${ }^{[6,26,28-30]}$

Motivated by the findings concerning the water-tolerant Lewis acidity of anatase, we designed an anatase synthesis in the presence of citric acid (CA) in excess, i.e. CA:Ti(IV) $=1.1 \mathrm{~mol} / \mathrm{mol}$. Under this condition, we hypothesised that the formation of Lewis sites should be maximised because of the stabilising effect of $C A$ on the particle formation, which prevents the growth of the anatase crystallites and should also generate defects in the structure. In addition, as the hybrid- $\mathrm{TiO}_{2}$ is not calcined, but employed in the reaction as synthesised, it is plausible to expect that the hybrid-organic-inorganic anatase (hybrid- $\mathrm{TiO}_{2}$ ) will feature the presence of Brønsted acid sites derived from the presence of CA's free carboxylic groups.

Herein, we demonstrate hybrid- $\mathrm{TiO}_{2}$ to be a highly efficient catalyst for the direct production of HMF from glucose in water. This report is organised into five parts. The first compares the structural and textural properties of hybrid- $\mathrm{TiO}_{2}$ against those from regular anatase obtained from the hydrolysis of titanium(IV) isopropoxide. Ti K-edge XANES results reveal hybrid- $\mathrm{TiO}_{2}$ to contain a fraction of five-fold coordinatively unsaturated $\mathrm{Ti}(\mathrm{IV})$ sites larger than that of regular anatase. The second presents the catalytic results. Hybrid- $\mathrm{TiO}_{2}$ allows for HMF yields up to ninetimes higher than those achieved by regular anatase in water. The third part presents the co-operation of $\mathrm{CA}$ and anatase in the catalytic system, indicating that the coordinatively unsaturated $\mathrm{Ti}(\mathrm{IV})$ is associated with the isomerisation of glucose to fructose, while citric acid anchored on the anatase structure is responsible for the conversion of fructose into HMF. The fourth part shows the results of recycling experiments, demonstrating the good stability of the hybrid- $\mathrm{TiO}_{2}$ catalyst. Finally, in the fifth part, in-depth characterisation of hybrid- $\mathrm{TiO}_{2}$ by using $\mathrm{Ti} \mathrm{K}$-edge XANES and TGA-MS reveal the fate of the Lewis and Brønsted acid sites throughout the catalyst recycling. 


\section{Results and Discussion}

To explore our working hypothesis regarding the effect of $\mathrm{CA}$ on the structural and textural features of hybrid- $\mathrm{TiO}_{2}$, the material properties of hybrid- $\mathrm{TiO}_{2}$ were compared against those of anatase obtained from a conventional hydrolysis route beginning with titanium(IV) isopropoxide with no added CA. This material (regular 'inorganic' anatase) is referred to as " $\mathrm{i}-\mathrm{TiO}_{2}$."

\section{Material characterisation}

Both hybrid- $\mathrm{TiO}_{2}$ and $\mathrm{i}-\mathrm{TiO}_{2}$ show diffraction patterns characteristic of anatase phase (Figure 1). However, the XRD pattern for the hybrid- $\mathrm{TiO}_{2}$ exhibits broadened reflections peaks, indicating that this material is formed by crystallites smaller than those from $\mathrm{i}-\mathrm{TiO}_{2}$. In fact, the average crystallite sizes are $5 \mathrm{~nm}$ and $10 \mathrm{~nm}$ for hybrid- $-\mathrm{TiO}_{2}$ and $\mathrm{i}-\mathrm{TiO}_{2}$, respectively as presented in Table 1.

Table 1. Textural properties and average crystallite size of $\mathrm{i}-\mathrm{TiO}_{2}$ and hybrid- $\mathrm{TiO}_{2}$

\begin{tabular}{ccccc}
\hline Material & $\begin{array}{c}\text { BET } \\
\text { specific } \\
\text { area } \\
\left(\mathrm{m}^{2} \mathrm{~g}^{-1}\right)\end{array}$ & $\begin{array}{c}\text { Pore } \\
\text { volume } \\
\left(\mathrm{cm}^{3} \mathrm{~g}^{-1}\right)\end{array}$ & $\begin{array}{c}\text { BHJ average } \\
\text { pore diameter } \\
(\mathrm{nm})\end{array}$ & $\begin{array}{c}\text { Mean } \\
\text { crystalline } \\
\text { size } \\
(\mathrm{nm})\end{array}$ \\
\hline $\mathrm{i}^{\mathrm{a}-\mathrm{TiO}}{ }_{2}$ & 105 & 0.14 & 8.4 & 10 \\
$\mathrm{Hybrid}-\mathrm{TiO}_{2}$ & 376 & 0.30 & 3.2 & 5 \\
[a] Estimated from XRD data. & & & \\
\hline
\end{tabular}

Displayed in Figure 2 are the HR-TEM images of the $\mathrm{TiO}_{2}$ catalysts. In good agreement with the crystallite sizes estimated from XRD data, HR-TEM images show $\mathrm{i}_{-} \mathrm{TiO}_{2}$ consists of independent crystallites of $8-15 \mathrm{~nm}$ in size, while hybrid- $\mathrm{TiO}_{2}$ is an agglomerate of very small crystallites $(2-5 \mathrm{~nm})$. The small crystallite size of hybrid- $\mathrm{TiO}_{2}$ is associated with the strong interaction of citric acid and Ti(IV) species. There is abundant evidence that carboxylic acid ligands, which are released during the condensation of titanium complexes, adsorb readily onto the freshly-forming surface of $\mathrm{TiO}_{2}$ hindering the particle growth. ${ }^{[31-33]}$ This process is expected to create $\mathrm{O}^{2-}$ vacancies on $\mathrm{Ti}(\mathrm{IV})$ centre, i.e. Lewis acid sites.

The textural properties of the materials were investigated by $\mathrm{N}_{2}$ adsorption-desorption isotherm profiles (Figure 3). Table 1 summarises the textural properties. Hybrid- $\mathrm{TiO}_{2}$ exhibits type IV isotherm, indicating the presence of ink-bottle-shaped mesopores. By contrast, $\mathrm{i}-\mathrm{TiO}_{2}$ shows a mixed type II and type IV isotherm, indicating the presence of non-structural meso/macroporosity in addition to structural ink-bottle-shaped mesopores. Markedly, hybrid- $\mathrm{TiO}_{2}$ exhibits a surface area 3.6times larger than that of $\mathrm{i}-\mathrm{TiO}_{2}$. Furthermore, the pore volume of hybrid- $\mathrm{TiO}_{2}$ is twice as large as that of $\mathrm{i}-\mathrm{TiO}_{2}$. Both materials exhibit a wide pore-size distribution as shown in Figure $\mathrm{S} 1$, Supporting Information.

To assess the nature of acid sites created by the synthetic methodologies, infrared (IR) absorption spectra from pyridine adsorbed on hybrid- $\mathrm{TiO}_{2}$ and $\mathrm{i}-\mathrm{TiO}_{2}$ were collected (Figure 4). Prior to the adsorption of pyridine, these materials were evacuated at $120^{\circ} \mathrm{C}$ for $22 \mathrm{~h}$ under dynamic vacuum $\left(2 \cdot 10^{-5} \mathrm{mbar}\right)$ $\mathrm{CA}$ in hybrid- $\mathrm{TiO}_{2}$ is stable under these conditions, as revealed by TGA-MS analysis (vide infra, Figure 8).

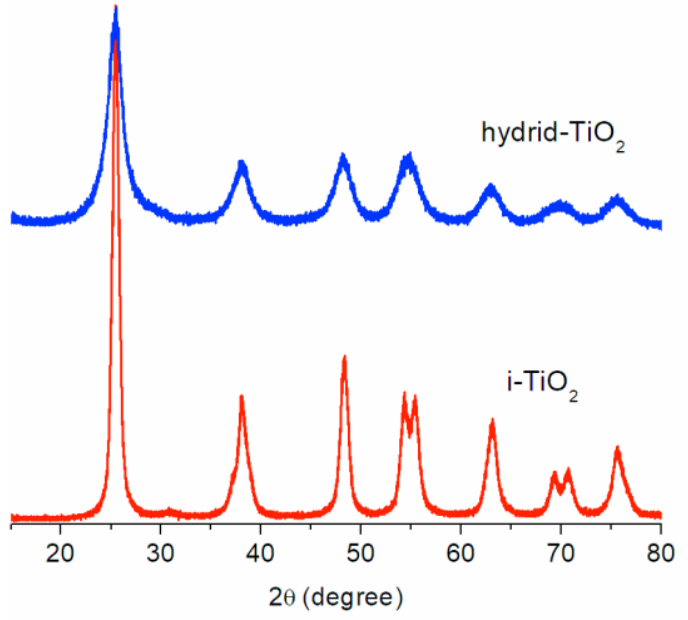

Figure 1. XRD patterns of hybrid- $\mathrm{TiO}_{2}$ and $\mathrm{i}-\mathrm{TiO}_{2}$ exhibiting anatase phase.

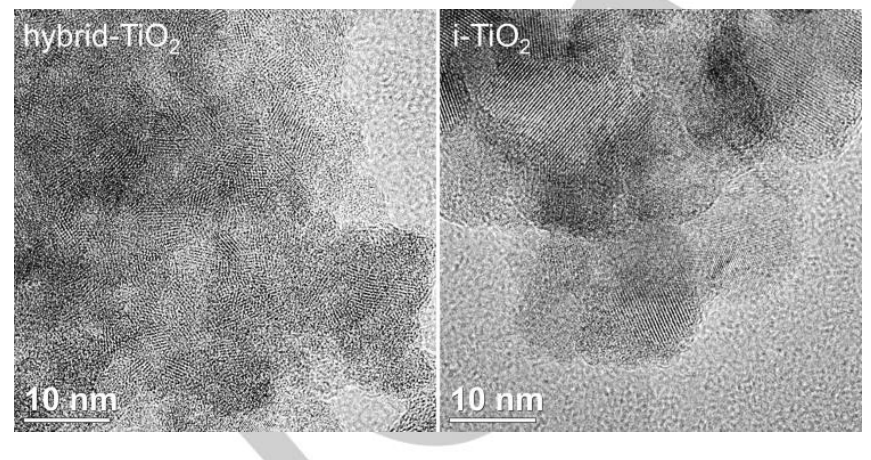

Figure 2. HR-TEM images of hybrid- $\mathrm{TiO}_{2}$ and $\mathrm{i}-\mathrm{TiO}_{2}$ xerogels.

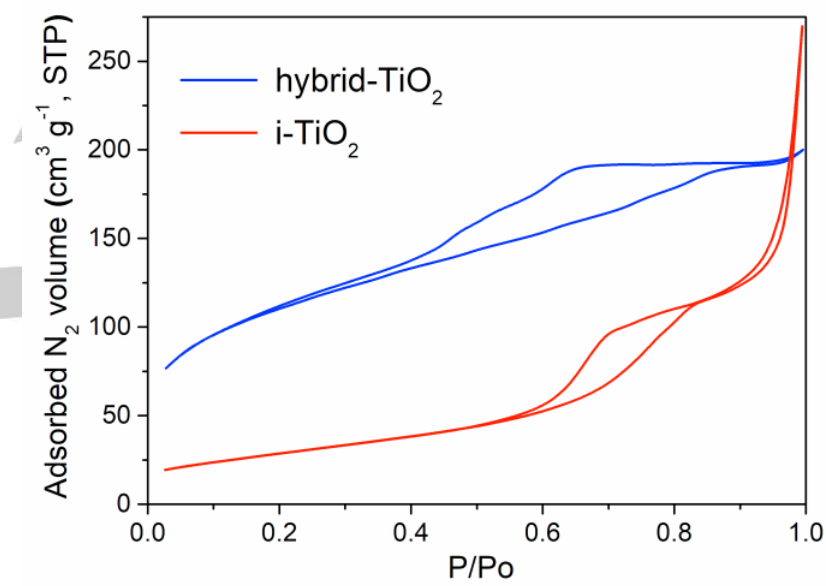

Figure 3. $\mathrm{N}_{2}$ adsorption-desorption isotherms of the $\mathrm{i}-\mathrm{TiO}_{2}$ and hybrid- $\mathrm{TiO}_{2}$.

Unfortunately, both CA and citrate ions show IR adsorption bands in the same region of the characteristic bands for adsorbed pyridine (IR spectrum of hybrid- $\mathrm{TiO}_{2}$ displayed in grey colour in Figure 4; detailed signal assignment listed in Table S1). Despite this, it was possible to identify the presence of both Brønsted (1540 and $1640 \mathrm{~cm}^{-1}$, regions highlighted in blue colour) ${ }^{[45]}$ and 
Lewis (1444 and $1602 \mathrm{~cm}^{-1}$, regions highlighted in green colour) ${ }^{[45]}$ acid sites on hybrid- $\mathrm{TiO}_{2}$ surface. Clearly, the band intensities for both Brønsted and Lewis acid sites are stronger for hybrid- $-\mathrm{TiO}_{2}$ than those found for $\mathrm{i}-\mathrm{TiO}_{2}$. This observation suggests that a larger quantity of both acid sites is present in hybrid- $\mathrm{TiO}_{2}$, which may be attributable to the larger surface area of hybrid- $\mathrm{TiO}_{2}$.

Considering the Brønsted acid sites, hybrid- $\mathrm{TiO}_{2}$ exhibits a much more intense band for pyridinium ion, compared against $\mathrm{i}-\mathrm{TiO}_{2}$. More importantly, it is apparent that there is a ligand exchange occurring on $\mathrm{Ti}(\mathrm{IV})$ centre upon exposing hybrid- $\mathrm{TiO}_{2}$ to pyridine ('Py'). In fact, the spectrum of pyridine adsorbed on hybrid- $\mathrm{TiO}_{2}$ also displays a very intense IR absorption band characteristic for R-COOH species (centred at about $1675 \mathrm{~cm}^{-1}$ : region highlighted in pale red colour), while the spectrum of evacuated hybrid- $\mathrm{TiO}_{2}$ only shows the characteristic IR bands for the carboxylate ion form (broad band between 1320 and 1450 $\mathrm{cm}^{-1}$ and shoulder at $1530 \mathrm{~cm}^{-1}$ ). We rationalise these observations in the IR spectra to correspond to a release of carboxylate ligands from $\mathrm{Ti}(\mathrm{IV})$ centre, enabling the chemical equilibrium R-COO${ }^{-}+\left(\mathrm{Ti}_{-} \mathrm{OH}_{2}\right)^{+} \leftrightharpoons \mathrm{R}-\mathrm{COOH}+(\mathrm{Ti}-\mathrm{OH})$ to be established on the surface. Overall, these observations suggest important features of the interaction between $\mathrm{CA} /$ citrate and Ti(IV) in hybrid- $\mathrm{TiO}_{2}$. Thermodynamically, the fact that pyridinium ion (' $\mathrm{PyH}^{+}$') exhibits a $\mathrm{p} K_{\mathrm{a}}$ value of 5.25 close to those of CA $\mathrm{p} K_{\mathrm{a}}$ values ( $\mathrm{p} K_{\mathrm{a} 1}$ 3.13, $\mathrm{p} K_{\mathrm{a} 2} 4.76$ and $\mathrm{p} K_{\mathrm{a} 3}$ 6.40) implies that appreciable quantities of both $\mathrm{R}-\mathrm{COOH}$ and $\left[\mathrm{RCOO}^{-}\right]\left[\mathrm{pyH}^{+}\right]$ species are present on the surface, as pinpointed by IR spectroscopy. Kinetically, the fact that the characteristic IR band of $\mathrm{R}-\mathrm{COOH}$ is present in the spectrum of pyridine adsorbed on hybrid- $\mathrm{TiO}_{2}$ strongly suggests that the interaction between $\mathrm{Ti}(\mathrm{IV})$ and some populations of $\mathrm{RCOO}^{-}$groups is labile, enabling the coexistence of Lewis [Ti(IV)——, where ' $\square$ ' denotes a vacancy] and Brønsted acid sites $\left(\mathrm{R}-\mathrm{COOH}\right.$ or $\mathrm{Ti}-\mathrm{OH}_{2}{ }^{+}$) in equilibrium on the surface under the reaction conditions.

To provide further insight into the local order of $\mathrm{Ti}(\mathrm{IV})$ in $\mathrm{i}-\mathrm{TiO}_{2}$ and hybrid- $\mathrm{TiO}_{2}$, Ti-edge XANES analyses were performed. Normalised Ti-edge XANES results are presented in Figure 5. The pre-edge features present are highly sensitive to subtle changes in the $\mathrm{Ti}(\mathrm{IV})$ chemical environment. These features are closely related to the degree of $d-p$ orbital mixing, and the

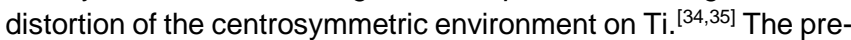
edge peaks denoted by ' $\mathrm{P}_{1}$ ', ' $\mathrm{P}_{2}$ ', ' $\mathrm{P}_{2}$ '” and ' $\mathrm{P}_{3}$ ' correspond to the dipole-forbidden transitions $1 s$ to $3 d-4 p$ hybrid orbitals, characteristic of $\mathrm{Ti}(\mathrm{IV})$ ions with a pseudo-octahedral symmetry as that of anatase. Most importantly, according to Farges et al., ${ }^{[36]}$ $\mathrm{P}_{2}$ and $\mathrm{P}_{2}$ ' peaks are related to the presence of five-fold coordinated $\mathrm{Ti}(\mathrm{IV})$ centres $\left(\mathrm{TiO}_{5}\right)$. When exposed to the surface, these centres can act as Lewis acid sites. Compared to $\mathrm{i}-\mathrm{TiO}_{2}$, hybrid- $\mathrm{TiO}_{2}$ has a larger quantity of such five-fold coordinated $\mathrm{Ti}(\mathrm{IV})$ centres, as indicated by the stronger intensity of the $\mathrm{P}_{2}$ ' peak in the hybrid- $\mathrm{TiO}_{2}$ XANES spectrum. This finding agrees well with the more intense IR pyridine absorption bands characteristic for Lewis acid sites. Furthermore, pyridine adsorbed on Lewis acid sites of hybrid- $\mathrm{TiO}_{2}$ presents a blueshift by $5 \mathrm{~cm}^{-1}$ relative to that on $\mathrm{i}-\mathrm{TiO}_{2}$ (hybrid- $\mathrm{TiO}_{2}: 1607 \mathrm{~cm}^{-1}$ vs. $\mathrm{i}-\mathrm{TiO}_{2}: 1602 \mathrm{~cm}^{-1}$; Figure 4). This finding indicates that $\mathrm{Py} \cdots \mathrm{Ti}(\mathrm{IV})$ interaction is slightly stronger in hybrid- $\mathrm{TiO}_{2}$ than $\mathrm{i}-\mathrm{TiO}_{2}$, in line with $\mathrm{Ti}$ K-edge XANES, which demonstrates hybrid- $\mathrm{TiO}_{2}$ to present more coordinatively unsaturated $\mathrm{Ti}(\mathrm{IV})$ sites than $\mathrm{i}-\mathrm{TiO}_{2}$.

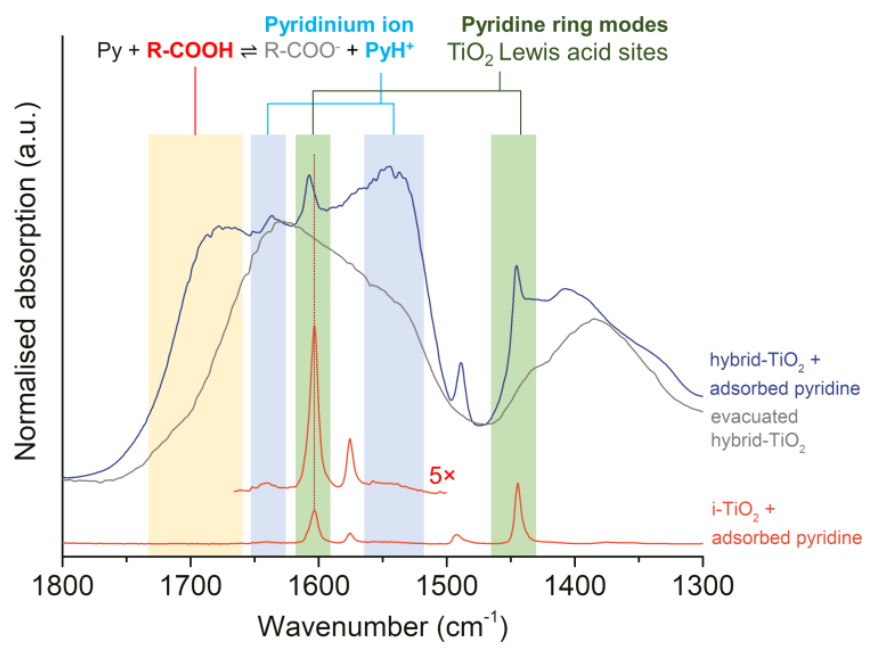

Figure 4. Infrared absorption spectra from pyridine adsorbed on hybrid- $\mathrm{TiO}_{2}$ and $\mathrm{i}-\mathrm{TiO}_{2}$. The FTIR spectrum displayed in greyish colour corresponds to that of the evacuated hybrid- $\mathrm{TiO}_{2}$ (in this case, the band at $1626 \mathrm{~cm}^{-1}$ corresponds to remnant water chemisorbed on $\mathrm{TiO}_{2}$, detailed band assignment listed in Table $\mathrm{S} 1)$. The red-dotted line at $1602 \mathrm{~cm}^{-1}$ serves as an eye guide to better show the blueshift observed for hybrid- $\mathrm{TiO}_{2}$ in the band characteristic of the interaction of pyridine and $\mathrm{TiO}_{2}$ Lewis acid sites.

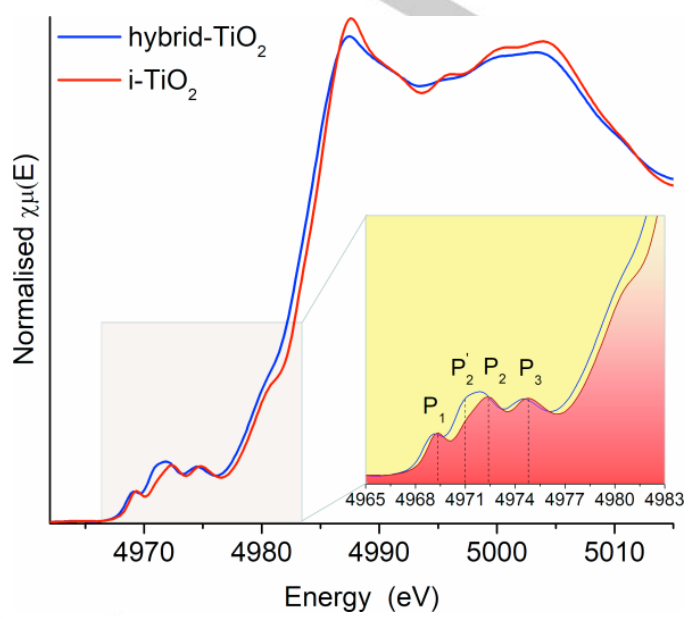

Figure 5. Normalised Ti K-edge XANES spectra of $\mathrm{i}-\mathrm{TiO}_{2}$ and hybrid- $\mathrm{TiO}_{2}$.

\section{Catalyst results}

Catalytic performance of hybrid- $-\mathrm{TiO}_{2}$ and $\mathrm{i}-\mathrm{TiO}_{2}$ was evaluated for the conversion of glucose into HMF in water. Figure 6 compares the catalysts with respect to the temporal evolution of glucose conversion and fructose and HMF formation at temperatures of 120,130 and $140{ }^{\circ} \mathrm{C}$. In general, hybrid- $\mathrm{TiO}_{2}$ showed an HMF productivity higher than $\mathrm{i}-\mathrm{TiO}_{2}$ under all conditions studied here. At $120^{\circ} \mathrm{C}$ for $7 \mathrm{~h}$, glucose conversions of $34 \%$ and $48 \%$, respectively, for $\mathrm{i}-\mathrm{TiO}_{2}$ and hybrid- $\mathrm{TiO}_{2}$ were achieved (Figure $6 \mathrm{a}$ and $6 \mathrm{~d}$ ). However, $\mathrm{HMF}$ yield was only $5 \%$ for $\mathrm{i}-\mathrm{TiO}_{2}$, while $19 \%$ for $\mathrm{TiO}_{2}-\mathrm{HYD}$ (Figure $6 \mathrm{a}$ and $6 \mathrm{~d}$ ). Total selectivity to minor identified selectivity to minor identified products (levulinic acid, formic acid, and furfural) was lower than $1 \%$. Increasing the reaction temperature to $130^{\circ} \mathrm{C}, \mathrm{HMF}$ production increased with both catalysts. Notably, however, is the superior performance of hybrid- $\mathrm{TiO}_{2}$. In fact, while with $\mathrm{i}-\mathrm{TiO}_{2}$ catalyst $\mathrm{HMF}$ yields varied from (Figure $6 \mathrm{~b}$ and $6 \mathrm{e}$ ) 3 to $8 \%$ after 0.5 to $7 \mathrm{~h}$ respectively, with 

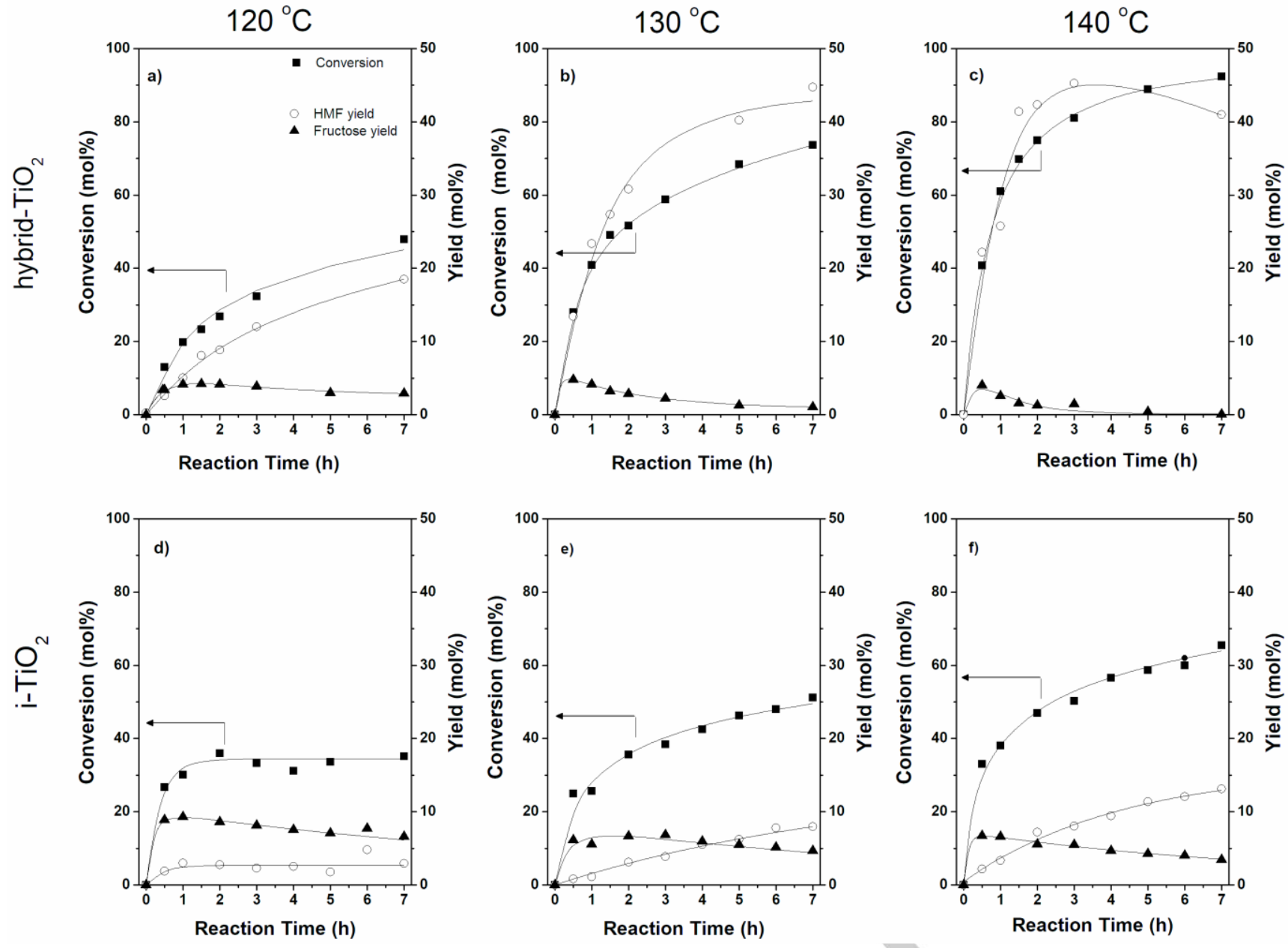

Figure 6. Catalytic activity for the conversion of glucose and yields of $\mathrm{HMF}$ and fructose at $120(\mathrm{~A}$ and $\mathrm{D}), 130$ (B and $\mathrm{E})$ and $140{ }^{\circ} \mathrm{C}(\mathrm{C}$ and $\mathrm{F})$ for hybrid-TiO 2 (top) and $\mathrm{i}-\mathrm{TiO}_{2}$ (bottom). Reaction conditions: water $(160 \mathrm{~mL})$, glucose $(3.26 \mathrm{~g})$, catalyst $\left(\mathrm{i}-\mathrm{TiO}_{2}\right.$ or hybrid- $\left.\mathrm{TiO}_{2}, 2.7 \mathrm{~g}\right), 500 \mathrm{rpm}$.

hybrid- $\mathrm{TiO}_{2} \mathrm{HMF}$ yields from 14 to $45 \%$ were achieved under the same conditions. Conversion attained at $130{ }^{\circ} \mathrm{C}$ for $\mathrm{i}-\mathrm{TiO}_{2}$ and hybrid- $\mathrm{TiO}_{2}$ was 48 and $77 \%$, respectively (Figure $6 \mathrm{~b}$ and $6 \mathrm{e}$ ). Finally, at $140{ }^{\circ} \mathrm{C}$ the conversion of glucose was $64 \%$ and $92 \%$ for $\mathrm{i}-\mathrm{TiO}_{2}$ and hybrid- $\mathrm{TiO}_{2}$, respectively (Figure $6 \mathrm{c}$ and $6 \mathrm{f}$ ). Nonetheless, a corresponding improvement in the HMF yield was not observed. Indeed, at $140{ }^{\circ} \mathrm{C}$, a $45 \% \mathrm{HMF}$ yield in the presence of hybrid- $-\mathrm{TiO}_{2}$ catalyst was achieved, which implies $56 \%$ selectivity at an $81 \%$ conversion after $3 \mathrm{~h}$. At high conversions, HMF yield decreases owing to HMF conversion to levulinic acid (releasing formic acid), which accounts for approx. $3 \%$ glucose equivalent consumption. The formation of humins constitutes, however, the main route of HMF degradation in our system at high glucose conversions, in line with previous observations from various catalytic systems. ${ }^{[1,4,6,8]}$

Kitano et al. ${ }^{[37]}$ reported $14 \%$ HMF yield for glucose conversion performed in the presence of titanate nanotubes with large surface area [i.e. $400 \mathrm{~m}^{2} \mathrm{~g}^{-1}$; reaction conditions: catalyst $(0.05 \mathrm{~g})$, glucose $(0.05 \mathrm{~g})$, water $(10 \mathrm{~mL})$, temperature $\left(120^{\circ} \mathrm{C}\right)$, $3 \mathrm{~h}$. The authors attributed the superior catalytic activity of the titanate nanotubes, compared to the other titania-based catalysts, to the large numbers of Lewis acid sites and the presence of effective Brønsted sites as well as the porous structure of the catalyst.

Recently, a notable result was also reported by Dutta et al. ${ }^{[7]}$, using mesoporous $\mathrm{TiO}_{2}$ nanospheres obtained via a sodium salicylate templating method, which allowed for the preparation of high surface area materials $\left(324 \mathrm{~m}^{-2} \mathrm{~g}^{-1}\right)$. In that study, a $25 \%$ HMF yield was obtained using a microwave-assisted heating $\left(120{ }^{\circ} \mathrm{C}\right.$ for $5 \mathrm{~min}$ ). Improved yields were attained (up to $37 \%$ ) when dimethyl sulfoxide (DMSO) instead of water was utilised as a solvent. While undoubtedly an important result, DMSO is unquestionably less environmentally friendly than water. Moreover, the separation of HMF from DMSO is often a costintensive process.

In summary, despite the drop in HMF selectivity at very high glucose conversions, to the best of our knowledge, HMF yields as high as $45 \%$ (Figure 6) constitute the highest HMF yields reported so far for the glucose conversion performed in water with a standard batch reactor operating with a conventional heating system. Similar high yields of HMF produced from glucose in water were obtained in the presence of phosphate-niobia catalysts. However, the process requires high catalyst loadings $($ e.g. catalyst/substrate ratio $=10) .{ }^{[38]}$ Yields similar to those 
presented in this report were only attained with the use of organic solvents ${ }^{[7,18,19,22]}$ or biphasic systems. ${ }^{[23,25,29]}$ Notably, in the case of biphasic systems, the continuous removal of HMF from the sugar-containing aqueous phase greatly contributes to even higher HMF yields than those presented here. Nonetheless, this feature is rather associated with the reaction engineering than intrinsic catalyst performance

\section{The co-operation of CA and anatase}

To shed light on the individual roles of citric acid and anatase in the conversion of glucose to HMF in the presence of the hybrid$\mathrm{TiO}_{2}$, our strategy was to examine the system beginning with a mixture of $\mathrm{i}-\mathrm{TiO}_{2}$ and citric acid in water. Table 2 shows the glucose conversion and the selectivity to HMF and fructose.

Table 2. Selectivity to 5-hydroxymethylfurfural (HMF) and fructose at similar glucose conversions.

\begin{tabular}{|c|c|c|c|c|}
\hline \multirow[t]{2}{*}{ Entry } & \multirow{2}{*}{$\begin{array}{l}\text { Catalytic } \\
\text { system }\end{array}$} & \multirow{2}{*}{$\begin{array}{c}X \\
(\%)\end{array}$} & \multicolumn{2}{|c|}{ Selectivity (\% mol C) } \\
\hline & & & Fructose & HMF \\
\hline 1 & Citric acid ${ }^{[\mathrm{b}]}$ & 7 & 10 & 31 \\
\hline 2 & $\mathrm{i}-\mathrm{TiO}_{2}[\mathrm{a}]$ & 22 & 26 & 5 \\
\hline 3 & $\begin{array}{l}\mathrm{i}-\mathrm{TiO}_{2}+ \\
\text { Citric acid }{ }^{[\mathrm{b}]}\end{array}$ & 23 & 18 & 41 \\
\hline 4 & Hybrid- $-\mathrm{TiO}_{2}{ }^{[\mathrm{a}]}$ & 28 & 17 & 48 \\
\hline
\end{tabular}

[a] Reaction temperature $130^{\circ} \mathrm{C}$. [b] Reaction temperature $1400^{\circ} \mathrm{C}$. Temporal reaction monitoring profiles are presented in Supporting Information (Figure S3).

CA exhibits a modest catalytic activity for glucose conversion (Entry 1). In this experiment, a $7 \%$ conversion of glucose was achieved at $140{ }^{\circ} \mathrm{C}$ for $7 \mathrm{~h}$, the selectivity to HMF was $31 \%$. In the presence of $\mathrm{i}-\mathrm{TiO}_{2}$, a $22 \%$ conversion of glucose into fructose (at $26 \%$ selectivity) and HMF (at $5 \%$ selectivity) was obtained (Entry 2). The presence of citric acid in the catalytic system (Entry 3 and 4) significantly improved selectivity to HMF by eight- to nine-times, compared to $\mathrm{i}_{-} \mathrm{TiO}_{2}$ (Entry 2). As revealed by FTIR spectroscopy, $\mathrm{CA}$ adsorbs on the surface $\mathrm{i}-\mathrm{TiO}_{2}$ creating surface citrate species comparable to those found in hybrid- $\mathrm{TiO}_{2}$ (Figure S2). Nonetheless, hybrid- $\mathrm{TiO}_{2}$ is more active and selective to $\mathrm{HMF}$ than the mixture of $\mathrm{i}-\mathrm{TiO}_{2}$ and $\mathrm{CA}$. In fact, a $23 \%$ conversion was only achieved in the presence of $\mathrm{i}_{-} \mathrm{TiO}_{2}$ and CA (Entry 3 ) at $140{ }^{\circ} \mathrm{C}$ for $3 \mathrm{~h}$. In contrast, for hybrid- $\mathrm{TiO}_{2}$ (Entry 4), a $28 \%$ conversion was achieved under milder conditions $\left(130^{\circ} \mathrm{C}\right.$ for $\left.30 \mathrm{~min}\right)$. Overall, these results indicate a co-operative effect of anatase surface, which appears to catalyse the isomerisation of glucose into fructose, and CA that catalyses the conversion of fructose into HMF. In this context, compared to $\mathrm{i}-\mathrm{TiO}_{2}$, the better performance of hybrid- $\mathrm{TiO}_{2}$ for the isomerisation step seems to be associated with the presence of anatase Lewis acid sites. Importantly, the results from Table 2 starkly contrast to those by Souza and coworkers, ${ }^{[8]}$ who showed highly concentrated aqueous organic acids solutions (e.g. a $20 \%$ acetic acid/water or $50 \%$ lactic acid/water) to be capable of catalysing the conversion of hexoses into HMF. In that report, HMF yields up to $43 \%$ and $26 \%$ from fructose and glucose, respectively, were reported.

\section{Catalyst recycling experiments}

The potential reusability of hybrid- $\mathrm{TiO}_{2}$ was explored by four successive catalyst uses. After each catalyst test, hybrid- $\mathrm{TiO}_{2}$ was collected, washed with water, and dried at $140^{\circ} \mathrm{C}$ overnight. Logically, the spent catalyst was not calcined to remove humins as a common practice in this research field, as this would also decompose the CA content chemically bounded to $\mathrm{TiO}_{2}$. Figure 7 summarises the results obtained from the recycling experiments carried out in the presence of hybrid- $\mathrm{TiO}_{2}$.

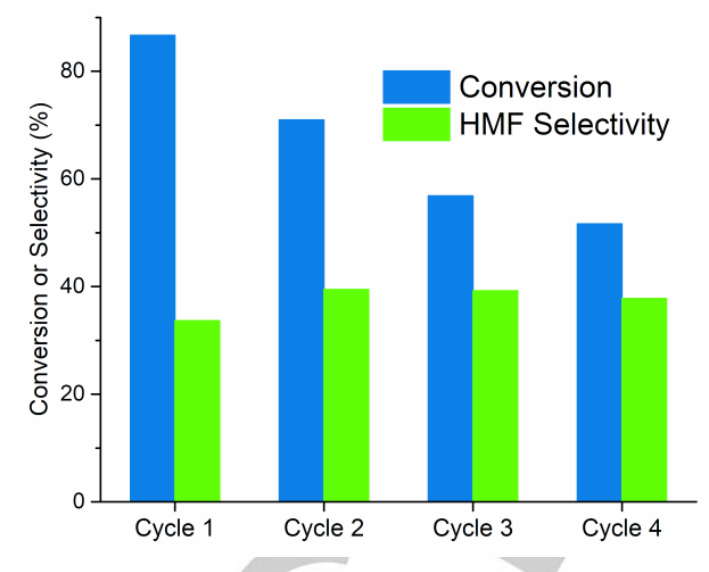

Figure 7. Catalyst recycling tests over hybrid- $-\mathrm{TiO}_{2}$. Reaction conditions: water $(160 \mathrm{~mL})$, glucose $(3.3 \mathrm{~g})$, hybrid- $\mathrm{TiO}_{2}(3.0 \mathrm{~g}), 500 \mathrm{rpm}, 140^{\circ} \mathrm{C}$ for $5 \mathrm{~h}$.

Figure 7 shows a gradual decrease in glucose conversion while HMF selectivity remains approximately constant after each recycling run. Surprisingly, even for Cycle 4, selectivity to HMF $(38 \%)$ are much superior to those achieved by $\mathrm{i}-\mathrm{TiO}_{2}$ in the first use at similar glucose conversion (selectivity to HMF: $16 \%$, as inferred from Figure 6f, results for the reaction mixture at $3 \mathrm{~h}$ ). As demonstrated by the XRD patterns and HR-TEM imaging, hybrid$\mathrm{TiO}_{2}$ retained its structural features throughout the recycling experiments (Figures S4 and S5). Nonetheless, a change in the material colour was observed. The material transformed from white (fresh catalyst) to pale yellow and finally brown in colour after the $4^{\text {th }}$ recycling run. Both colour change and a decline in conversion can be attributed to the accumulation of humins over the catalysts surface, which blocks the catalysts active sites.$^{[1,4,40,42,43]}$ However, even without calcination steps to remove humins, ${ }^{[43]}$ hybrid- $\mathrm{TiO}_{2}$ could still enable an $\mathrm{HMF}$ yield of $20 \%$ after the $4^{\text {th }}$ reaction run.

\section{The fate of CA throughout the recycling experiment}

$\mathrm{CA}$ is a strong chelating agent which has found use as a stabiliser in several nanomaterial syntheses. This fact cast doubts on the possibility of leaching of CA from the hybrid- $\mathrm{TiO}_{2}$. In fact, Mudunkotuwa and Grassian ${ }^{[44]}$ found the adsorption of citric acid to be an irreversible process at room temperature, regardless of the medium $\mathrm{pH}$. However, despite these previous results, the fact that a suprastoichiometric quantity of CA was employed in the synthesis of hybrid- $\mathrm{TiO}_{2}$ suggests that leaching of $\mathrm{CA}$ from the catalyst may eventually take place in the catalyst recycling. To address whether there is CA leaching from hybrid- $\mathrm{TiO}_{2}$, the material was subjected to a hydrothermal treatment with no added 
glucose simulating the catalyst test conditions $\left(500 \mathrm{rpm}, 140^{\circ} \mathrm{C}\right.$, $7 \mathrm{~h}$ ). We chose this approach to avoid deposition of humins on the material, which complicates the evaluation of CA leaching by TGA-MS or elemental analysis. Following the simulated reaction tests, the fresh and spent catalysts were characterised by elemental analysis (Table 3) and thermogravimetric analysis (TGA-MS, Figure 8).

Table 3. C-content present in hybrid- $\mathrm{TiO}_{2}$ before and after simulated reaction tests.

\begin{tabular}{lll}
\hline Entry & Material & C-content $(\%)$ \\
\hline 1 & Fresh hybrid-TiO 2 & $4.5 \pm 0.1$ \\
2 & ${\text { After } 1^{\text {st }} \text { simulated reaction }}$ & $3.1 \pm 0.1$ \\
3 & After $2^{\text {nd }}$ simulated reaction & $2.5 \pm 0.1$ \\
4 & After $3^{\text {rd }}$ simulated reaction & $2.1 \pm 0.1$
\end{tabular}

[a] Simulated reaction conditions: hybrid- $\mathrm{TiO}_{2}(3.0 \mathrm{~g}), \mathrm{H}_{2} \mathrm{O}(160 \mathrm{~mL})$, $140{ }^{\circ} \mathrm{C}, 500 \mathrm{rpm}, 7 \mathrm{~h}$.

Table 3 reveals that $\mathrm{C}$-content present in the hybrid- $\mathrm{TiO}_{2}$ markedly decreased (from $4.5 \pm 0.1 \%$ to $3.1 \pm 0.1 \%$ ) after the first simulated reaction run. Importantly, in the successive runs, the Ccontent reduced more gradually (from $3.1 \pm 0.1 \%$ to $2.5 \pm 0.1 \%$ for the $2^{\text {nd }}$ run, and to $2.1 \pm 0.1 \%$ for the $3^{\text {rd }}$ run). Despite the decrease in $\mathrm{C}$-content in hybrid- $\mathrm{TiO}_{2}$ no substantial change in the FTIR spectrum of the spent catalyst was detected (Figure S2).

Figure 8 shows the TGA profiles for the materials. According to the MS results, the first weight loss $\left(30-120^{\circ} \mathrm{C}\right)$ is associated with the elimination of water. The second and third weight losses, $\left(170-500^{\circ} \mathrm{C}\right)$ are related to the thermal decomposition of $\mathrm{CA}$, as inferred from the $\mathrm{MS}$ results for the $\mathrm{CO}_{2}$ monitoring. Interestingly, the onset temperature in which the $\mathrm{CO}_{2}$ release initiates gradually shifts (from ca. 170 to $200{ }^{\circ} \mathrm{C}$ ) upon the catalyst reutilisation (as indicated by a blue-coloured arrow in Figure $8 \mathrm{c}$ ). This observation indicates that the remaining $\mathrm{CA}$ in the hybrid- $\mathrm{TiO}_{2}$ is slightly more strongly bounded to anatase structure and, therefore, still playing a role in the structural stabilisation of hybrid- $\mathrm{TiO}_{2}$ under reaction conditions. Moreover, XRD analysis of spent hybrid- $\mathrm{TiO}_{2}$ reveals that the apparent crystallite size underwent no significant change throughout the recycling experiments $(5 \mathrm{~nm}$, Table S2). As expected, the decrease in the second and third weight losses agrees with the reduction in C-content observed for the hybrid$\mathrm{TiO}_{2}$ material after the simulated reactions. Nonetheless, there is a mismatch between the profile of $\mathrm{C}$-content decrease and the sustainability of the catalyst performance (Figure 8). This observation suggests that the loss in catalytic performance should be associated not only with the leaching of loosely-bound CA but also with other transformations in the anatase structure, which are difficult to resolve using XRD owing to the nanocrystalline nature of hybrid- $\mathrm{TiO}_{2}$.

To shed light on the changes occurring in the local order of $\mathrm{Ti}(\mathrm{IV})$ in the materials upon the leaching of loosely-bounded CA, XANES analyses of the spent catalysts obtained from the simulated reactions were performed. The pre-edge features of the normalised Ti-edge XANES spectra are presented in Figure 9.

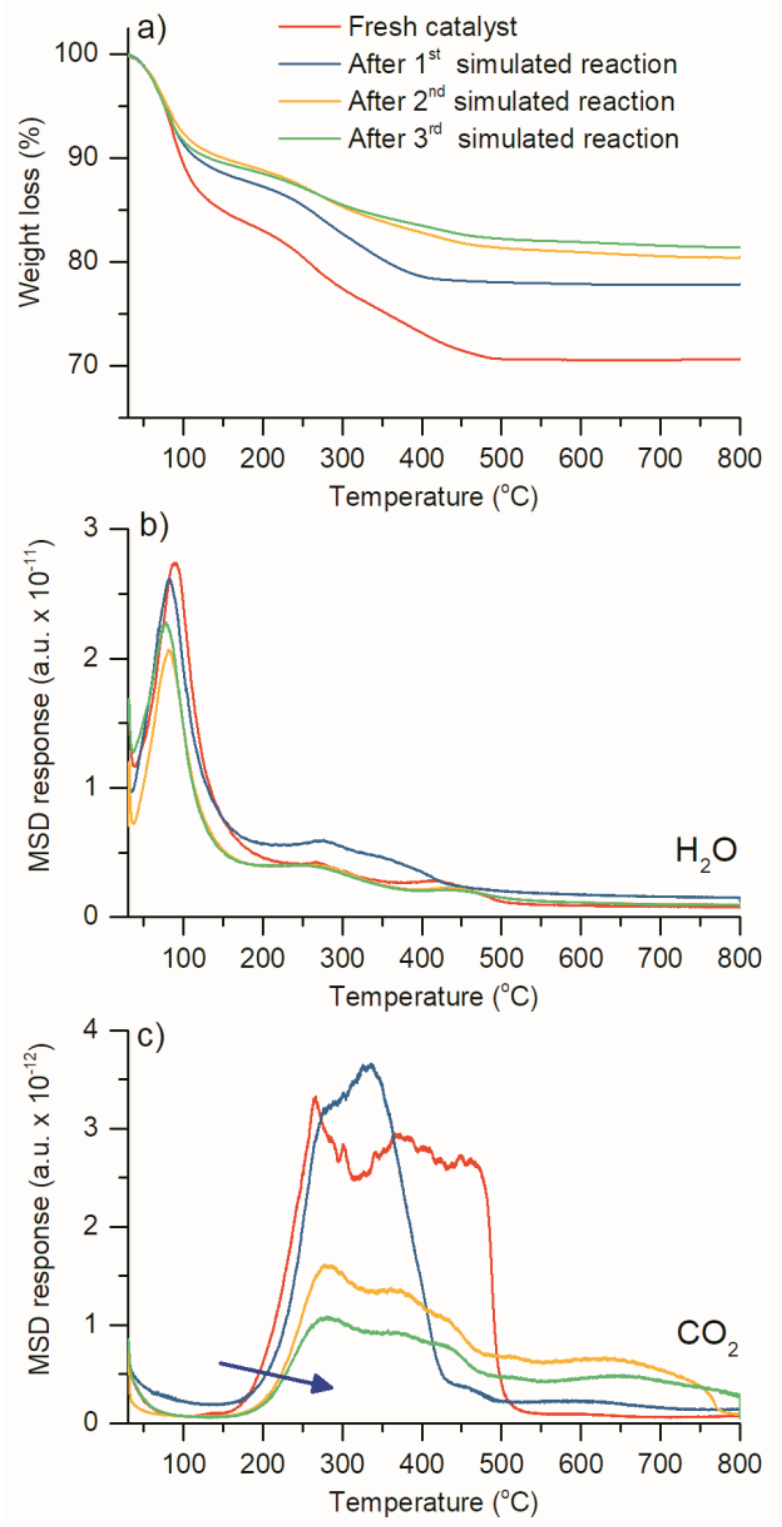

Figure 8. TGA-MS of hybrid- $\mathrm{TiO}_{2}$ before and after simulated reactions: a) TGA curves; b) MSD response for water (m/z: 18); c) MSD response for $\mathrm{CO}_{2}(\mathrm{~m} / \mathrm{z}$ : 44). The blue-colour arrow on the diagram 'c' indicates the shift of onset temperature for the $\mathrm{CA}$ decomposition. Simulated reaction conditions: $\mathrm{H}_{2} \mathrm{O}$ $(160 \mathrm{~mL})$, hybrid- $\mathrm{TiO}_{2}(3.0 \mathrm{~g}), 500 \mathrm{rpm}, 140^{\circ} \mathrm{C}, 7 \mathrm{~h}$.

Throughout the recycling experiments, the pre-edge features of the hybrid- $\mathrm{TiO}_{2}$ tend to near to those of $\mathrm{i}-\mathrm{TiO}_{2}$, indicating that there is a slight decrease in the quantity of fivefold coordinated $\mathrm{Ti}(\mathrm{IV})$ centres. This observation suggests that the strong interaction between $\mathrm{Ti}(\mathrm{IV})$ centres and citric acid is conducive to the preservation of the nanostructured features of hybrid- $-\mathrm{TiO}_{2}$ throughout the recycling experiments. Moreover, the resilience of fivefold coordinated Ti(IV) centres after successive cycles of hydrothermal treatment (simulated reactions) demonstrates the stability of these water-tolerant Lewis sites. 


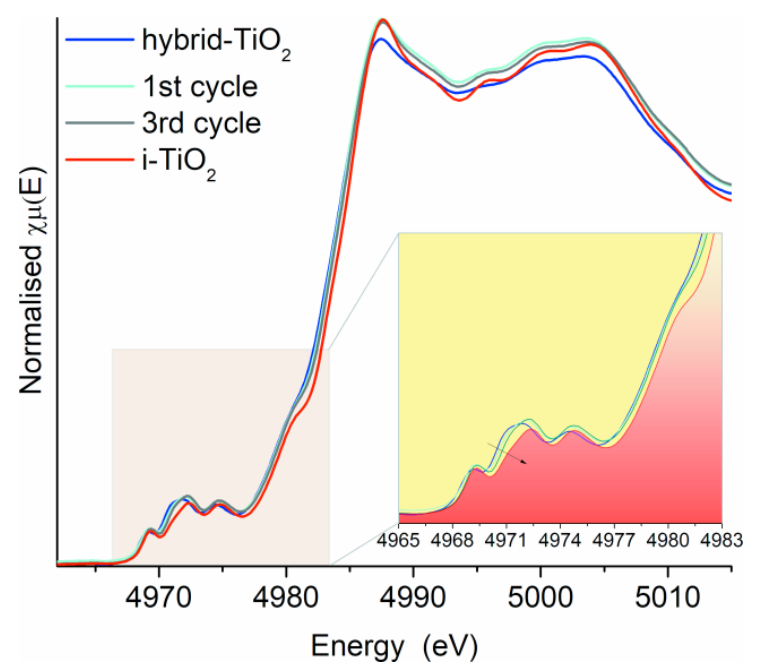

Figure 9. Pre-edge features of Ti K-edge XANES spectra of the as-synthesised hybrid- $\mathrm{TiO}_{2}$ catalysts (dark blue), after 1 cycle of simulated catalytic reaction (light blue), after the third cycle (grey) and $\mathrm{i}-\mathrm{TiO}_{2}$ (red, provided for comparison).

\section{Conclusions}

The synthesis of anatase in the presence of a suprastoichiometric quantity of $\mathrm{CA}$ generates a nanocrystalline hybrid-organicinorganic material with improved catalytic properties for the conversion of glucose into HMF in water under mild conditions. In fact, hybrid- $\mathrm{TiO}_{2}$ enabled high $\mathrm{HMF}$ yields (45\%) in a monophasic batch reactor. Surprisingly, even after four cycles of catalyst use, without a calcination step to remove humins from the catalyst surface, hybrid- $\mathrm{TiO}_{2}$ was still able to render a $29 \% \mathrm{HMF}$ yield.

Ti-edge XANES was a powerful tool for the characterisation of $\mathrm{Ti}$ coordination showing an enhanced presence of five-fold coordinated $\mathrm{Ti}(\mathrm{IV})$ centres that are associated with the formation of Lewis acid sites on the anatase surface of the hybrid- $\mathrm{TiO}_{2}$. The current results provide compelling evidence for the stability of water-tolerant Lewis acidity of hybrid- $\mathrm{TiO}_{2}$.

Besides the key roles of CA in the formation of Lewis sites, $\mathrm{CA}$ also retards the degradation of the catalysts structural features throughout the recycling experiments. In addition, as the hybrid- $\mathrm{TiO}_{2}$ is not calcined, but employed in the reaction as synthesised, we could verify the hypothesis that Brønsted acid sites associated with the presence of $\mathrm{CA}$ in the hybrid- $\mathrm{TiO}_{2}$ play a role in the conversion of fructose into HMF. Nonetheless, more work is still required for a clear designation of the level of participation of leached and $\mathrm{TiO}_{2}$-bounded $\mathrm{CA}$ species in the catalysis for the conversion of fructose into HMF.

\section{Experimental Section}

\section{Catalysts Synthesis}

$\mathrm{TiO}_{2}$ catalysts were synthesised via sol-gel (i- $\left.\mathrm{TiO}_{2}\right)$ and hydrothermal methods (hybrid- $-\mathrm{TiO}_{2}$ ). Both procedures are described hereafter. All chemicals purchased were used without further purification.

For the synthesis of hybrid- $\mathrm{TiO}_{2}, \mathrm{TiCl}_{4}(9 \mathrm{~mL}, 82 \mathrm{mmol}$, Merck) was poured into ice-cold deionised water $(200 \mathrm{~mL})$ under vigorous stirring. Next, citric acid (17.3 g, $90 \mathrm{mmol}$, Sigma-Aldrich) was immediately added to the mixture. In sequence, the suspension was refluxed at $140^{\circ} \mathrm{C}$ for $16 \mathrm{~h}$.
Finally, the solid was washed with hot water several times until pH 7. The solid was dried in an oven at $140{ }^{\circ} \mathrm{C}$ overnight, rendering the hybrid- $\mathrm{TiO}_{2}$, which was employed here as the catalyst.

For the synthesis of $\mathrm{i}-\mathrm{TiO}_{2}$, titanium isopropoxide (12 mL, Aldrich) was added to 2-propanol (12 mL, Merck) under stirring. Water $(6 \mathrm{~mL})$ was added to the mixture. Stirring was maintained for $1 \mathrm{~h}$. The solution was then allowed to age for $24 \mathrm{~h}$. The product was then dried at $80^{\circ} \mathrm{C}$ for $6 \mathrm{~h}$ and calcined at $450^{\circ} \mathrm{C}$ for $16 \mathrm{~h}$.

\section{Catalyst Characterisation}

X-ray diffraction (XRD) patterns were obtained at the XPD beamline at the LNLS/CNPEM. The beamline energy was $8.0 \mathrm{keV}$ and the XRD data collected using a linear detector (Mythen $1 \mathrm{k}$ ). Identification of crystalline phases was obtained from ICSD files. The crystallite sizes for $\mathrm{TiO}_{2}$ were estimated by using the Scherrer equation.

Nitrogen adsorption-desorption isotherms were measured at $-196^{\circ} \mathrm{C}$ on a Quantachrome Autosorb-1C automatic analyser. Samples were degassed at $120^{\circ} \mathrm{C}$ for $13 \mathrm{~h}$ before isotherms were measured. The specific surface area values were determined using the BET model. The total pore volume was derived from the amount of gas absorbed at a relative pressure of $\mathrm{P} / \mathrm{P}_{0}=0.95$.

The morphology of the $\mathrm{TiO}_{2}$ crystallites was investigated by using an HRTEM JEOL-JEM $2100 \mathrm{~F}$ operating at $200 \mathrm{kV}$ at the LNNano/CNPEM, with a resolution of $0.19 \mathrm{~nm}$.

XAFS experiments were carried out at the Brazilian synchrotron laboratory (LNLS) at the XAFS1 beamline. The measurements at the Ti K-edge (4966 $\mathrm{eV}$ ) were carried out in transmission mode at ambient temperature. The monochromator energy calibration was verified measuring a Ti metal foil. Samples were prepared by deposition of powders onto a micropore membrane. The spectra were analysed using Athena and Artemis software packages version 0.9.25.

FTIR spectra were collected on a Nicolet FT-IR-6700 spectrometer in the range of 4000 to $1000 \mathrm{~cm}^{-1}$ with a resolution of $2 \mathrm{~cm}^{-1}$. and 128 scans for signal accumulation. Sample preparation: sample powder was pressed, rendering a thin pellet. The sample pellet was transferred into a homemade IR cell equipped with $\mathrm{NaCl}$ windows. First, the sample was evacuated at $120^{\circ} \mathrm{C}$ for $22 \mathrm{~h}$ under dynamic vacuum $\left(2.10^{-5} \mathrm{mbar}\right)$. After cooling to room temperature, the sample spectrum was obtained. Then, the samples were exposed to pyridine vapor until the equilibrium vapor pressure and the cell was kept under this condition for an additional $24 \mathrm{~h}$. Next, the IR cell was heated up to $120^{\circ} \mathrm{C}$ for $22 \mathrm{~h}$ under dynamic vacuum $\left(2.10^{-5} \mathrm{mbar}\right)$. After cooling down to room temperature, the IR spectrum of adsorbed pyridine on the sample was collected.

Thermogravimetric analyses were carried out on a NETZSCH TG 209F1 Libra coupled to an MS detector. TG curves were obtained from the samples $\left(40 \mathrm{mg}\right.$ ) heated at $10^{\circ} \mathrm{C} \mathrm{min}-1$ from 30 to $800^{\circ} \mathrm{C}$ under synthetic air flow in a ceramic sample holder.

$\mathrm{CHN} / \mathrm{O}$ elemental analyses were performed in triplicate for samples $(2 \mathrm{mg})$ on a Vario Micro Cube elemental analyser (Elementar). Average values of the triplicate measurements are reported.

\section{Catalyst Tests}

The catalytic tests were performed using a Hastelloy batch reactor (300 mL, Parr Instruments). Glucose (Sigma) and catalyst were loaded into the reactor with an appropriated catalyst/glucose mass ratio, with $160 \mathrm{~mL}$ of total reaction volume (2 wt\% glucose concentration). The reactor was purged with nitrogen and the temperature raised to reaction 
temperature $\left(120,130\right.$ or $\left.140{ }^{\circ} \mathrm{C}\right)$ with an agitation speed of $500 \mathrm{rpm}$. At each point of the kinetic curve, a sample from the reactor was taken for product and glucose quantification. Therefore, each kinetic curve was done by repeating several times an experiment under a given condition for various durations.

HPLC analyses were performed using a Waters 1525 chromatograph at the CTBE/CNPEM equipped with Aminex HPX-87H - Bio-rad capillary column and Acclaim $120 \mathrm{C} 18$ Dionex column for analysis using refractive index (RI) and UV detectors. Glucose conversion (X,\% mol/mol), product yield $(\mathrm{Y}, \% \mathrm{~mol} / \mathrm{mol})$ and selectivity $(\mathrm{S}, \% \mathrm{~mol} / \mathrm{mol})$ were determined according to the equations:

$$
\begin{gathered}
X=\left(1-\frac{G_{f}}{G_{0}}\right) \times 100 \\
Y_{i}=\frac{\# C_{i}}{6} \frac{P_{i}}{G_{0}} \times 100 \\
S_{i}=\frac{Y_{i}}{X} \times 100
\end{gathered}
$$

where $G_{0}(\mathrm{~mol} / \mathrm{L})$ denotes the glucose concentration in the feed and $G$ (mol/L) denoting after reaction values. \#Ci and $\mathrm{Pi}$ are the carbon number and the concentration of the product $i(\mathrm{~mol} / \mathrm{L})$ (fructose, HMF, levulinic acid etc.), respectively. The standard deviation was calculated, and the maximum values are given as follows: $\pm 3 \%$ for glucose conversion, $\pm 1 \%$ for HMF yield and finally, $\pm 0.8 \%$ for fructose yield.

\section{Acknowledgements}

The authors are grateful to LNLS/CNPEM and CNPq for the financial support, CTBE/CNPEM for chromatographic analysis of reaction products and LNNano for the TEM microscope. We would also like to thank Guilherme. P. Nogueira for the catalyst preparation and reactions. RR acknowledges the support provided by the ERC Consolidator Grant (LIGNINFIRST, Project Number: 725762) for this collaborative work.

Keywords: anatase, water-resistant Lewis acid, hydrothermal synthesis, citric acid, glucose dehydration, HMF

[1] A. A. Rosatella, S. P. Simeonov, R. F. M. Frade, C. A. M. Afonso, Green Chem. 2011, 13, 754-793.

[2] I. Jiménez-Morales, J. Santamaría-González, A. Jiménez-López, P. Maireles-Torres, Fuel 2014, 118, 265-271.

[3] M. J. Climent, A. Corma, S. Iborra, Chem. Rev. 2011, 111, 1072-133.

[4] R. Van Putten, J. C. Van Der Waal, E. De Jong, C. B. Rasrendra, H. J. Heeres, J. G. De Vries, Chem. Rev., 2013, 113, 1499-1597.

[5] M. Watanabe, Y. Aizawa, T. lida, R. Nishimura, H. Inomata, App Catal. A Gen. 2005, 295, 150-156.

[6] R. Noma, K. Nakajima, K. Kamata, M. Kitano, S. Hayashi, M. Hara, J. Phys. Chem. C 2015, 117, 16028-16033.

[7] S. Dutta, S. De, A. K. Patra, M. Sasidharan, A. Bhaumik, B. Saha, Appl. Catal. A Gen. 2011, 409-410, 133-139.

[8] R. L. de Souza, H. Yu, F. Rataboul, N. Essayem, Challenges 2012, 3, 212-232.

[9] A. Chareonlimkun, V. Champreda, A. Shotipruk, N. Laosiripojana Bioresour. Technol. 2010, 101, 4179-86.

[10] G. Yang, E. A. Pidko, E. J. M. Hensen, ChemSusChem 2013, 6
$1688-1696$.

[11] E. A. Pidko, V. Degirmenci, E. J. M. Hensen, ChemCatChem 2012 , 4, 1263-1271.

[12] G. Yang, E. A. Pidko, E. J. M. Hensen, J. Catal. 2012, 295, 122-132.

[13] X. Qi, M. Watanabe, T. M. Aida, R. L. Smith, Catal. Commun. 2008 9, 2244-2249.

[14] E. F. L. J. Anet, in Adv. Carbohydr. Chem., 1964, pp. 181-218.

[15] C.-H. Kuo, A. S. Poyraz, L. Jin, Y. Meng, L. Pahalagedara, S.-Y. Chen, D. A. Kriz, C. Guild, A. Gudz, S. L. Suib, Green Chem. 2014, 16, 785.

[16] Y. Yang, C. Hu, M. M. Abu-Omar, J. Mol. Catal. A Chem. 2013, 376 98-102.

[17] a) Y. J. Pagán-Torres, T. Wang, J. M. R. Gallo, B. H. Shanks, J. A. Dumesic, ACS Catal. 2012, 2, 930-934; b) R. Carrasquillo-Flores, M. Käldström, F. Schüth, J. A. Dumesic, R. Rinaldi, ACS Catal. 2013, 3, 993-997.

[18] L. Hu, G. Zhao, X. Tang, Z. Wu, J. Xu, L. Lin, S. Liu, Bioresour. Technol. 2013, 148, 501-507.

[19] M. Zhang, K. Su, H. Song, Z. Li, B. Cheng, Catal. Commun. 2015, 69, $76-80$.

[20] T. Wang, Y. J. Pagán-Torres, E. J. Combs, J. A. Dumesic, B. H Shanks, Top. Catal. 2012, 55, 657-662.

[21] L. Qi, Y. F. Mui, S. W. Lo, M. Y. Lui, G. R. Akien, I. T. Horváth, ACS Catal. 2014, 1470-1477.

[22] J. Liu, H. Li, Y.-C. Liu, Y.-M. Lu, J. He, X.-F. Liu, Z.-B. Wu, S. Yang, Catal. Commun. 2015, 62, 19-23.

[23] L. Atanda, A. Silahua, S. Mukundan, A. Shrotri, G. Torres-Torres, J. Beltramini, RSC Adv. 2015, 5, 80346-80352.

[24] J. Zhang, L. Lin, S. Liu, Energy Fuels 2012, 26, 4560-4567.

[25] L. Atanda, S. Mukundan, A. Shrotri, Q. Ma, J. Beltramini, ChemCatChem 2015, 7, 781-790.

[26] K. Nakajima, R. Noma, M. Kitano, M. Hara, J. Phys. Chem. C 2013 117, 16028-16033.

[27] Luis Augusto Barbosa Cortez, Catalytic Dehydration of C6 Carbohydrates for the Production of Hydroxymethylfurfural (HMF) as a Versatile Platform Chemical, PhD Thesis, São Paulo, 2010.

[28] E. Nikolla, Y. Román-Leshkov, M. Moliner, M. E. Davis, ACS Catal. 2011, 1, 408-410.

[29] K. Nakajima, R. Noma, M. Kitano, M. Hara, J. Mol. Catal. A Chem 2014, 388-389, 100-105.

[30] H. Shintaku, K. Nakajima, M. Kitano, N. Ichikuni, M. Hara, ACS Catal. 2014, 4, 1198-1204.

[31] Y. Li, N. H. Lee, D. S. Hwang, J. S. Song, E. G. Lee, S. J. Kim, Langmuir 2004, 20, 10838-10844.

[32] H. Yin, Y. Wada, T. Kitamura, T. Sumida, Y. Hasegawa, S. Yanagida, J. Mater. Chem. 2001, 12, 378-383.

[33] Y. Liu, C. yan Liu, Z. ying Zhang, Chem. Eng. J. 2008, 138, 596-601

[34] F. Leroux, P. J. Dewar, M. Intissar, G. Ouvrard, L. F. Nazar, J. Mater Chem. 2002, 12, 3245-3253.

[35] Z. Y. Wu, G. Ouvrard, P. Gressier, C. R. Natoli, Phys. Rev. B 1997, 55, 10382-10391.

[36] F. Farges, G. E. Brown, J. J. Rehr, Phys. Rev. B 1997, 56, 4,1809 1819.

[37] M. Kitano, K. Nakajima, J. N. Kondo, S. Hayashi, M. Hara, J. Am Chem. Soc. 2010, 132, 6622-6623.

[38] K. Nakajima, Y. Baba, R. Noma, M. Kitano, J. Kondo, S. Hayashi, M. Hara, J. Am. Chem. Soc. 2011, 133, 4224-4227.

[39] L. Atanda, A. Shrotri, S. Mukundan, Q. Ma, M. Konarova, J. Beltramini, ChemSusChem 2015, 8, 2907-2916. 
[40] T. Wang, M. W. Nolte, B. H. Shanks, Green Chem. 2014, 16, 548572.

[41] S. Dutta, S. De, A. K. Patra, M. Sasidharan, A. Bhaumik, B. Saha, Appl. Catal. A Gen. 2011, 409-410, 133-139.

[42] A. Mukherjee, M.-J. Dumont, V. Raghavan, Biomass and Bioenergy 2014, 72, 143-183.
C.-H. Kuo, A. S. Poyraz, L. Jin, Y. Meng, L. Pahalagedara, S.-Y. Chen, D. A. Kriz, C. Guild, A. Gudz, S. L. Suib, Green Chem. 2014, 16, 785. I. A. Mudunkotuwa, V. H. Grassian, J. Am. Chem. Soc. 2010, 132, 14986-14994.

[45] 


\section{Entry for the Table of Contents}

Layout 1:

\section{FULL PAPER}

With a lemon please! Herein, citric acid was employed in a facile hydrothermal synthesis method for the production of a hybrid-organicinorganic anatase. This material was directly studied here as the catalyst for the conversion of glucose to HMF. Yields up to $45 \%$ at glucose conversions up to $75 \%$ were achieved in water at $130^{\circ} \mathrm{C}$ in a monophasic batch reactor.

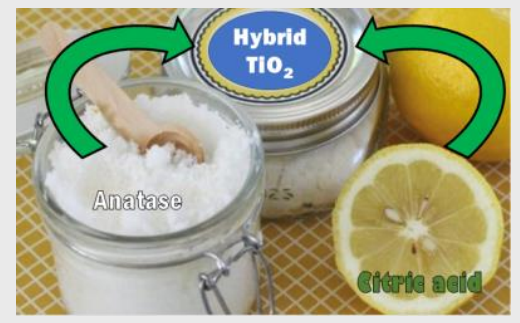

Carlos A. S. Lanziano, Silvia F. Moya Dean H. Barrett, Erico Teixeira-Neto, Reginaldo Guirardello, Felipe de Souto da Silva, Roberto Rinaldi* and Cristiane B. Rodella*

Page No. - Page No.

Hybrid-organic-inorganic anatase as a bifunctional catalyst for enhanced production of HMF from glucose in water 